\title{
THE CORROSION/DISSOLUTION BEHAVIOUR OF ALUMINIUM IN SOLUTIONS CONTAINING BOTH CHLORIDE AND FLUORIDE IONS
}

\author{
W. M. Carroll, M. Murphy and C. B. Breslin* \\ Chemistry Department, University College Galway, Ireland \\ * Chemistry Department, St Patricks College Maynooth, Kildare, Ireland
}

\begin{abstract}
The corrosion behaviour of aluminium in sodium chloride or sodium fluoride solution is at the present time reasonably well understood. In chloride solution, localised attack on the oxide is the most usual problem encountered. In fluoride solution, the $\mathrm{Al}_{2} \mathrm{O}_{3}$ film is initially found to be removed to be replaced by a complex oxyfluoride film which subsequently determines the corrosion behaviour. In the present work, potentiodynamic, potentiostatic, open circuit potential and impedance tests are used to elucidate the corrosion behaviour of aluminium in solutions containing both chloride and fluoride ions. It has been found that the presence of fluoride does not lead to localised attack, but that it modifies the surface oxide in such a way as to facilitate attack by chloride. Surprisingly however, for a fixed $0.5 \mathrm{M}$ chloride concentration, these effects of fluoride are only manifest in the concentration range $0.25-10^{-3} \mathrm{M}$ fluoride at $20^{\circ} \mathrm{C}$. Concentrations in excess of $0.25 \mathrm{M}$ have no apparent activating influence. At higher temperatures, lower fluoride levels are sufficient to cause these oxide modifications. The presence of fluoride even in very small quantities prevents 'film improvement' reactions similar to those observed in chloride only solutions.
\end{abstract}

\section{INTRODUCTION}

Aluminium and many of its alloys, which are stable in a wide range of electrolytes, can under certain conditions undergo intense localised attack in the presence of chloride and bromide ions. ${ }^{1-5}$ The conditions which facilitate this type of attack have been well documented in the literature over the years and various mechanisms which fit the experimental details have been proposed. ${ }^{6-9}$ Preferential attack at flaws in the developing film has been postulated as the initial step in the process, the subsequent steps depending on the environmental conditions. These activation steps are manifested by current increases on potentiostatic current-time plots, ${ }^{10,11}$ provided the passivation potential is close to the potentiodynamically determined pitting potential for the given solution.

The behaviour of aluminium in sodium fluoride electrolytes is very different to that observed with $\mathrm{Cl}^{-}$and $\mathrm{Br}^{-}$solutions. ${ }^{12}$ Here attack seems to be more general in nature, the net result being a gradual destabilisation of the oxide film and depending on the applied potential its replacement with a complex aluminium oxy-fluoride one. ${ }^{13}$ This film is less protective than the original oxide film. ${ }^{14}$

Because of this it was of interest to study the influence of the fluoride anion on the stability of films formed on $\mathrm{Al}$ in aqueous chloride solutions, particularly at low concentration levels. This is of importance because of the still widespread use of $\mathrm{Al}$ in many domestic and packaging applications.

Results of this nature have been obtained using potentiodynamic, potentiostatic, 
open-circuit potential and impedance measurements. Particular emphasis has been placed on the effects of increasing temperature on the overall stability of the films formed.

\section{EXPERIMENTAL METHOD}

Test specimens were obtained from $99.999 \% \mathrm{Al}$ sheets, $1.0 \mathrm{~mm}$ in thickness. Before use the samples were mechanically polished on a range of SiC emery paper to a 600 grit finish, washed in distilled water and cleaned in methanol and a unit area of $1.0 \mathrm{~cm}^{2}$ exposed to the test electrolyte. The d.c. electrochemical mesurements were performed in a thermostatted $\left( \pm 0.1^{\circ} \mathrm{C}\right)$ Pyrex glass cell with graphite auxiliary electrodes and a saturated calomel reference electrode (SCE). Where variations in the test solution temperature were investigated the reference electrode was maintained at room temperature. Measurements were carried out using a Thompson precision research potentiostat and the current measured by recording the potential drop across a standard resistor. Test solutions were prepared from reagent grade chemicals and distilled water. For d.c. measurements in chloride solutions only, the samples were initially held in the working electrolyte at an applied potential of $-2.0 \mathrm{~V}$ for a period of $5 \min$ prior to recording of data. For fluoride solutions (unless otherwise stated) measurements were commenced immediately on immersion of the sample in the electrolyte. For the addition of $\mathrm{NaF}$ after a pre-passivation period, $50 \mathrm{ml}$ portions were added to the original $100 \mathrm{ml}$ test solution with gentle agitation, the chloride concentration remaining constant. Potentiodynamic plots were recorded at a scan rate of $1.0 \mathrm{mVs}^{-1}$, and all potentials quoted are with respect to the SCE. Electrochemical impedance measurements were carried out using a Capcis March model CV2001 frequency response analyser in conjunction with a Capcis March interface. This instrumentation was interfaced to a $\mathrm{PC}$ for data acquisition and analysis using Corrsoft ${ }^{\circledR}$ Sheila software. Data were collected at frequencies ranging from $1 \mathrm{kHz}$ to $10 \mathrm{MHz}$. For measurements at the rest potential, two identical Al electrodes were used, while for measurements at an applied potential the cell arrangement was similar to that used for the d.c. measurements. Unless otherwise stated, the $\mathrm{pH}$ values of the various solutions were not adjusted and were in the range 5.5-6.0.

\section{EXPERIMENTAL RESULTS}

Some current decay profiles recorded for $\mathrm{Al}$ in $0.5 \mathrm{M} \mathrm{NaF}$ solution at different applied potentials are shown in Fig. 1(a). In each case an immediate current increase was detected on application of the potential, followed directly by a current decay. At low potentials a smooth current decay is observed, while the current turns from decreasing to increasing with higher applied potentials. However, at no stage are current fluctuations or oscillations observed on the decay profiles. In Fig. 1(b) the open circuit potential (OCP) time dependence for $\mathrm{Al}$ in $\mathrm{NaF}$ solution shows a shift in potential towards that of bare $\mathrm{Al}$ immediately on immersion followed by a gradual return to more noble values after a period of approximately $20 \mathrm{~min}$. Nyquist plots of the real vs imaginary components of impedance for each excitation frequency, recorded at the rest potential after different periods of immersion are shown in Fig. 2. The data obtained on initial immersion seem to indicate a purely activation controlled process, shifting after longer periods to a straight line, indicative of diffusion control and a reasonably passive surface. Shown in Fig. 3 is a typical open circuit potential-time plot for an oxide covered (air formed) Al sample immersed in $0.5 \mathrm{M} \mathrm{NaCl}$ solution. Addition of $\mathrm{NaF}\left(10^{-3} \mathrm{M}\right)$ to this solution after a $20 \mathrm{~min}$ passivation period results, in some cases, after an induction period $\tau$, in an exponential increase in potential in the active direction. A number of parameters were found to be dependent on the concentration of the NaF added. These included the magnitude of the steady-state potential, the value of the induction period and the tendency of the activated samples to revert to a passive state. In general a high degress of reproducibility was observed, the magnitude of the adopted potential varying by no more than $20 \mathrm{mV}$ during identical runs. These potential values 
(a)

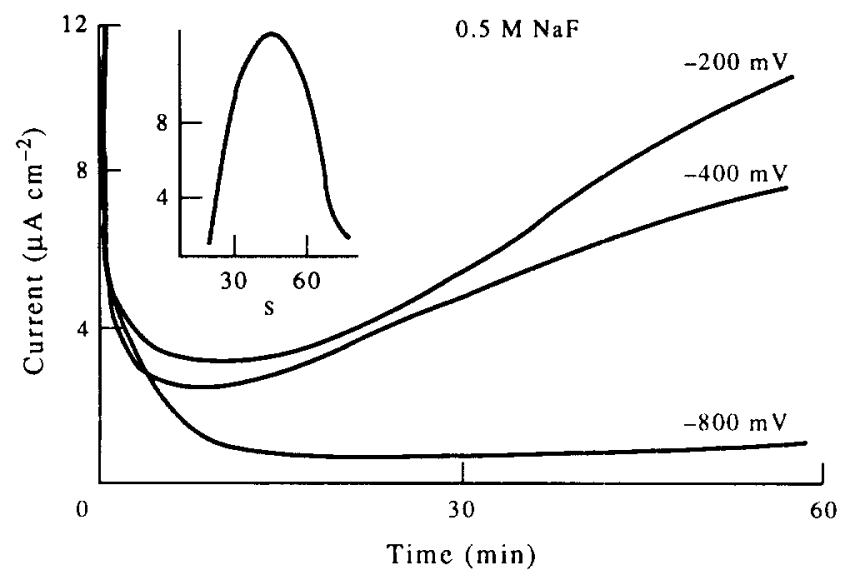

(b)

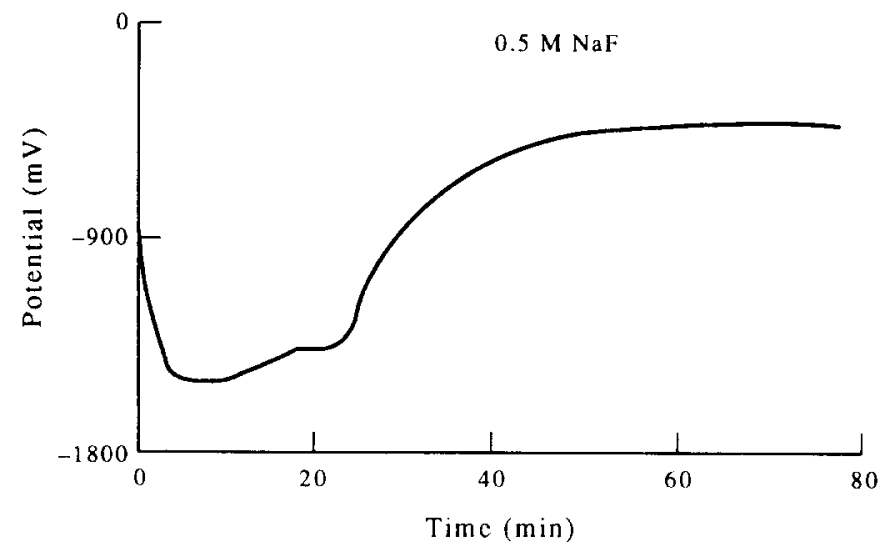

Fig. 1. (a) Current decay profiles, recorded for $\mathrm{Al}$ in $0.5 \mathrm{M} \mathrm{NaF}$ at the potentials indicated. Insert shows current time behaviour over the first $60 \mathrm{~s}$ at each potential.

(b) Open-circuit potential time variation for $\mathrm{Al}$ in $0.5 \mathrm{M} \mathrm{NaF}$ :

(recorded over a $12 \mathrm{~h}$ period) as a function of the $\mathrm{NaF}$ concentration are summarised in Table 1.

A similar series of experiments conducted in solutions where the fluoride ion was present from the outset gave similar results. These data clearly show that as the fluoride concentration is increased the adopted potential becomes progressively more active and the tendency towards repassivation is considerably reduced. It would be expected that potentiodynamic data would yield similar results. However, as indicated in Fig. 4, the pitting potentials measured in $\mathrm{NaCl}$ solutions containing $\mathrm{NaF}$ additions seem to be independent of the fluoride concentration. An anodic maximum, similar to that observed in the absence of $\mathrm{NaCl}$, was detected only with the $0.5 \mathrm{M} \mathrm{NaF}$ addition. Very little variation in the pitting potential is observed either, on changing the $\mathrm{pH}$ of the $\mathrm{Cl}^{-}+\mathrm{F}^{-}$solution (Table 2). These data seem to imply that the passive films formed in these solutions all have a similar resistance to pitting attack. 
In order to try to resolve this point, potentiostatic current time tests were carried out. Two different methods were employed; (i) the sample was activated at $-2.0 \mathrm{~V}$ for the usual 5-min period in the $\mathrm{NaCl}+\mathrm{NaF}$ solution and the current time data then recorded on application of the selected potential, or (ii) the required amount of $\mathrm{NaF}$ was added, after a 20 -min passivation period, to the original $0.5 \mathrm{M} \mathrm{NaCl}$ solution. Results obtained using the former method are shown in Fig. 5. These current-time plots are dominated by current peaks and fluctuations, the extent of this metastable attack and the magnitude of the passive current depending on the $\mathrm{F}^{-}$concentration. Thus for $\mathrm{NaF}$ concentrations $>10^{-4} \mathrm{M}$ and $<0.25 \mathrm{M}$ the surface films formed clearly have a lower resistance to localised attack. The impedance data shown in Fig. 6 seem to indicate that when the $\mathrm{Cl}^{-}$and $\mathrm{F}^{-}$concentrations are of the same order the extent of film instability or attack is considerably reduced. Thus the Nyquist plots show a reasonable degree of film stability even after $24 \mathrm{~h}$ of immersion in the $0.25 \mathrm{M}$ $\mathrm{Cl}^{-}+0.25 \mathrm{M} \mathrm{F}^{-}$solution. Results obtained using the second method of $\mathrm{F}^{-}$addition at the same applied potential are shown in Fig. 7. As before, a $10^{-4} \mathrm{M} \mathrm{NaF}$ addition has very little effect while a $10^{-3} \mathrm{M}$ addition resulted, after a delay period, in an increase in the passive current and a greater frequency of activation-repassivation events. These effects are intensified further with a $10^{-2} \mathrm{M}$ addition, the delay period being considerably reduced.

Impedance data, recorded after addition of $10^{-2} \mathrm{M} \mathrm{F}^{-}$to a sample immersed in $0.5 \mathrm{M} \mathrm{Cl}^{-}$at a potential of $-775 \mathrm{mV}$ are shown in Fig. 8. The $\mathrm{F}^{-}$was added after a $20 \mathrm{~min}$ passivation period in the chloride solution and the data recorded over a $24 \mathrm{~h}$ test period. The results seem clearly to indicate fairly active $\mathrm{Al}$ dissolution rates over the duration of the test period, in sharp contrast with the results for the $0.25 \mathrm{M} \mathrm{F}^{-}$ addition (Fig. 6).

The quality of the passive oxides formed on $\mathrm{Al}$ in aqueous halide solutions generally improve with time of passivation. ${ }^{2}$ It would be expected therefore that the destabilising effects exerted by $\mathrm{F}^{-}$ion would be dependent on the duration of the passivation period prior to its addition. The results presented in Fig. 9 show that this is indeed the case, the longer passivation periods giving rise to larger delay times before the current increases and activation events become more pronounced.

In potentiostatic tests, where conditions were such that pitting attack was not

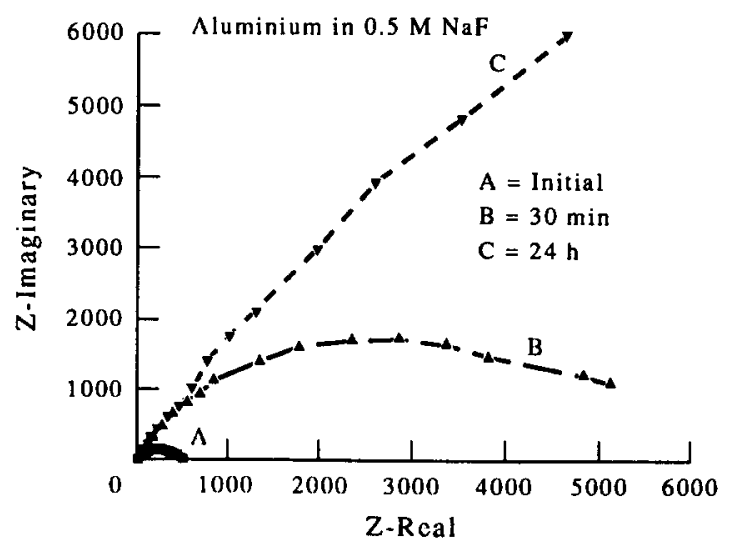

FIG. 2. Nyquist plot for $\mathrm{Al}$ in $0.5 \mathrm{M} \mathrm{NaF}$, recorded after the time periods indicated. 


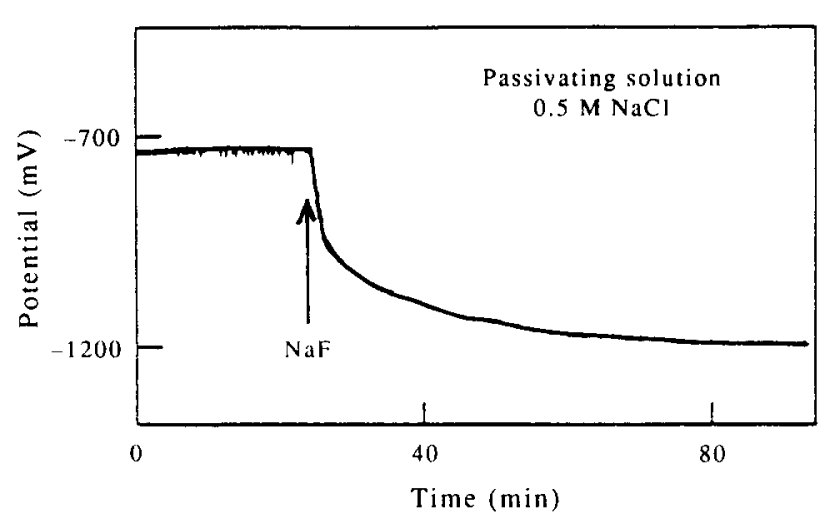

Fig. 3. Open-circuit potential time variation for $\mathrm{Al}$ in $0.5 \mathrm{M} \mathrm{NaCl}$ after addition (20 min) of $10^{-3} \mathrm{M} \mathrm{NaF}$.

favoured, the addition of $\mathrm{NaF}$ solution only gave rise to an increase in the current density, no fluctuations being detected.

Current-time plots recorded over extended periods of time after $\mathrm{F}^{-}$addition (Fig. 10a), did not indicate a reduction in the frequency or density of current fluctuations as was evident in the absence of $\mathrm{F}^{-}$(Fig. 10b). Thus the sequence of events leading to film improvement is not effective in this case.

Variation of the $\mathrm{NaCl}$ concentration in the interval $0.05-3.0 \mathrm{M}$ had very little influence on the activation process, regardless of the experimental technique employed. For example, the steady state open-circuit potential values tabulated as a function of the $\mathrm{NaCl}$ concentration (Table 3) show no appreciable variation even at the limits of 0.05 and $3.0 \mathrm{M}$.

\section{The influence of temperature}

Increasing the temperature of the test solution has a marked effect on the stability of the films formed on $\mathrm{Al}$ in the presence of fluoride. The open-circuit potential is shifted in the active direction, and as the potentiodynamic polarisation plots in Fig. 11 indicate the passive current is increased by several orders of magnitude. It is worth noting also that the $\mathrm{F}^{-}$concentration shows a much more pronounced influence on the pitting potential at this higher temperature. This temperature influence was again clearly evident from potentiostatic studies. The current time transients

Table 1. Steady-state potential as a function of $\left[\mathrm{F}^{-}\right],[\mathrm{NaCl}]=0.5 \mathrm{M}$

\begin{tabular}{lc}
\hline$\left[\mathrm{F}^{-}\right] / \mathrm{mol} \mathrm{dm}^{-3}$ & Potential $/ \mathrm{mV}$ \\
\hline $1.0 \times 10^{-2}$ & -1500 \\
$1.0 \times 10^{-3}$ & -1350 \\
$1.0 \times 10^{-4}$ & -1280 \\
$5.0 \times 10^{-5}$ & -1040 \\
$4.0 \times 10^{-5}$ & -980 \\
$1.0 \times 10^{-5}$ & $-840^{*}$ \\
\hline
\end{tabular}

* Repassivates after $4 \mathrm{~h}$. 


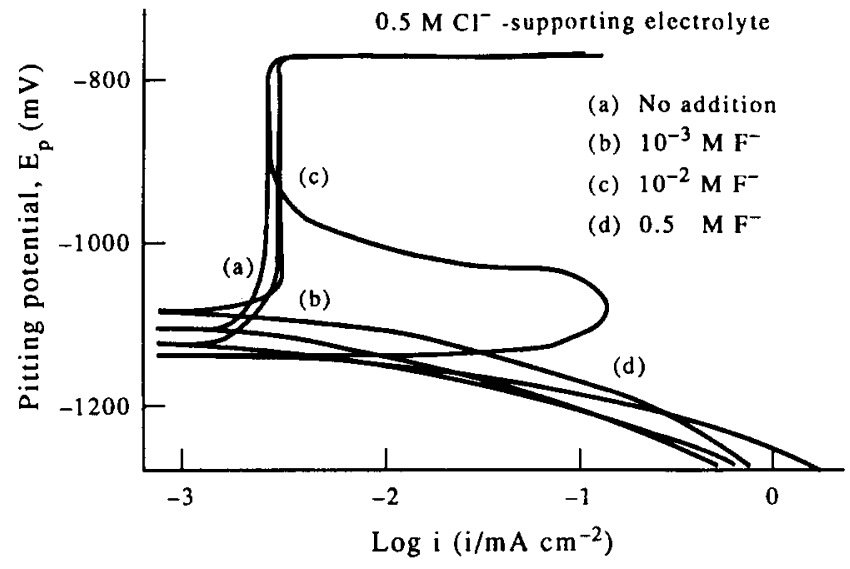

FIG. 4. Potentiodynamic polarization plots for $\mathrm{Al}$ in the solutions indicated.

$\left(E_{\text {app }}=-775 \mathrm{mV}\right.$ ) obtained on addition of $\mathrm{NaF}$ to a $0.5 \mathrm{M} \mathrm{NaCl}$ solution at $47^{\circ} \mathrm{C}$ giving rise to solutions of $10^{-3}$ and $10^{-4} \mathrm{M} \mathrm{NaF}$ are shown in Fig. 12. More intense fluctuations are observed with the higher $\mathrm{NaF}$ concentration and indeed complete activation occurred with a $10^{-2} \mathrm{M}$ addition. The instantaneous current increase observed with the $10^{-4}$ addition at $47^{\circ} \mathrm{C}$ does not occur at room temperature. Thus the minimum amount of fluoride necessary to give a reasonable degree of activity is reduced with increasing temperature.

\section{DISCUSSION}

The current-time data shown in Fig. 1(a) would seem to indicate clearly that on immersion of $\mathrm{Al}$ in fluoride solution, the air-formed oxide film is removed. With time, a new film, probably a complex oxyfluoride film forms ${ }^{13}$ the protective ability of which is potential dependent. No current peaks or fluctuations similar to those observed in $\mathrm{Cl}^{-}$and $\mathrm{Br}^{-}$solutions ${ }^{2}$ appear on the decay profiles indicating an absence of activation/repassivation events or metastable pitting. The OCP variation with time (Fig. 1b) and the impedance data in Fig. 2, would seem to support this line of reasoning. These data also indicate that the passivation characteristics and the

Table 2. Pitting potentials measured in

$0.5 \mathrm{M} \mathrm{Cl}^{-}+\mathrm{F}^{-}$SOLUTIONS ADJUSTED TO $\mathrm{pH}$ VALUES 5.5, 7 AND 9

\begin{tabular}{lcc}
\hline$\left[\mathrm{F}^{-}\right] / \mathrm{mol} \mathrm{dm}^{-3}$ & $\mathrm{pH}$ & $E_{\mathrm{p}} / \mathrm{mV}$ \\
\hline 0.0 & 5.5 & -720 \\
& 7.0 & -722 \\
& 9.0 & -738 \\
$10^{-2}$ & 5.5 & -738 \\
& 7.0 & -720 \\
$10^{-4}$ & 9.0 & -722 \\
& 5.5 & -718 \\
& 7.0 & -720 \\
& 9.0 & -723 \\
\hline
\end{tabular}




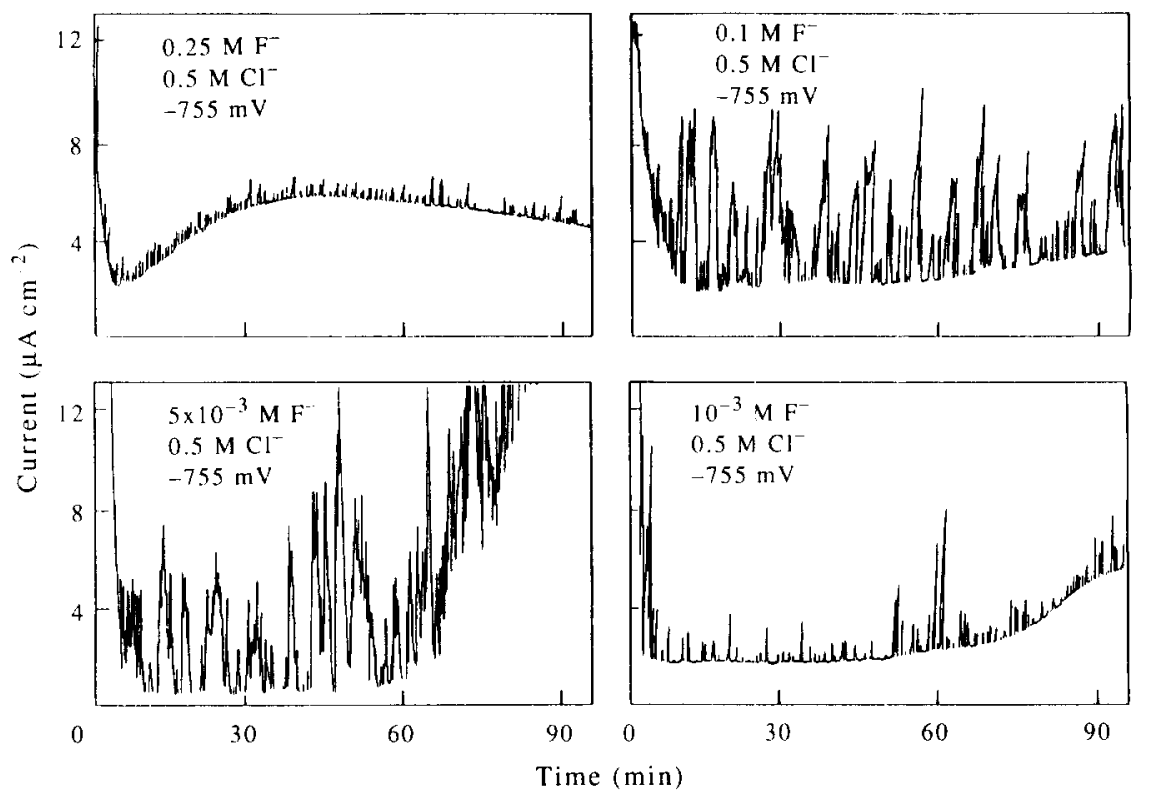

Fig. 5. Current time plots recorded for $\mathrm{Al}$ at $-755 \mathrm{mV}(\mathrm{SCE})$ in the indicated solutions.

composition of the newly formed oxyfluoride film are clearly time-dependent. Since $\mathrm{Al}$ and $\mathrm{Al}_{2} \mathrm{O}_{3}$ can form a range of stable fluoride complexes ${ }^{14-16}$ of varying degrees of solubility, the composition of this newly formed film is difficult to ascertain in any detail. Since the chloride ion does not form the same well defined range of complex salts with $\mathrm{Al},{ }^{17}$ attack by $\mathrm{Cl}^{-}$on oxide covered $\mathrm{Al}$ is generally localised in origin.

When both of these ions are present together in the test electrolyte it is not surprising that the corrosion behaviour would again be somewhat modified.

The OCP measurements presented in Fig. 3 and Table 1 point very obviously to a

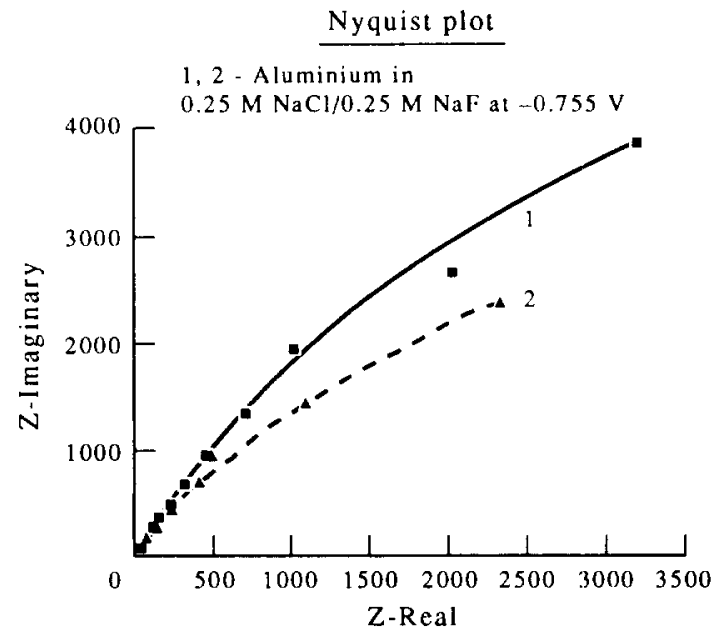

FIg. 6. Nyquist plots for Al held at a potential of $-755 \mathrm{mV}(\mathrm{SCE})$ in $0.25 \mathrm{M}$ $\mathrm{NaCl}+0.25 \mathrm{M} \mathrm{NaF}$ solution, recorded after (1) $15 \mathrm{~min}$ and (2) $24 \mathrm{~h}$ of immersion. 


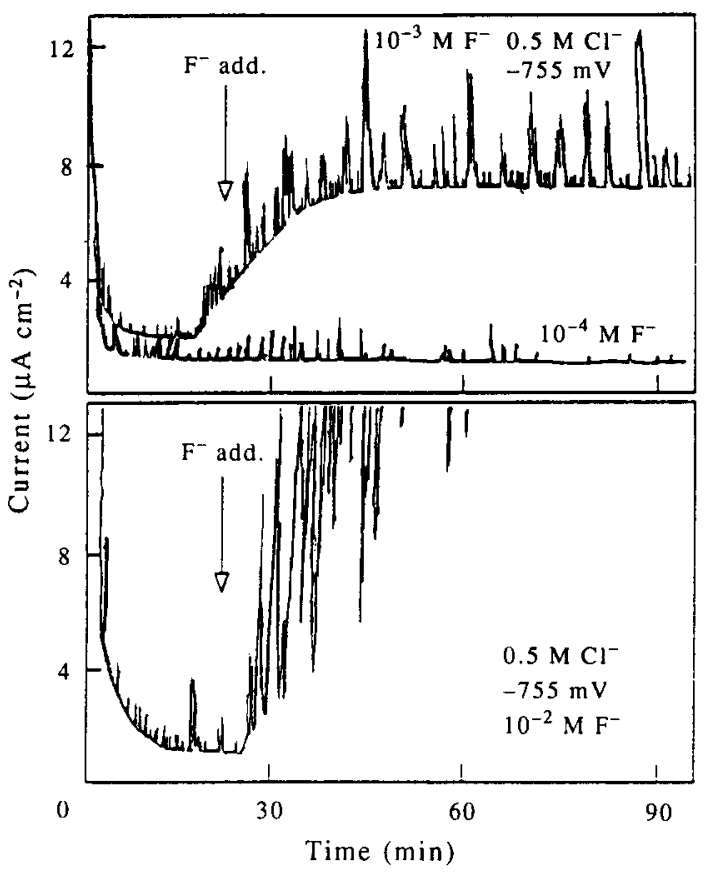

Fig. 7. Current decay profiles recorded for $\mathrm{Al}$ in $0.5 \mathrm{M} \mathrm{NaCl}$ at a potential of $-755 \mathrm{mV}(\mathrm{SCE}) ; \mathrm{NaF}$ was added after a 20 -min passivation period to give the $\mathrm{F}^{-}$concentrations indicated.

change in the overall activity of the test samples on addition of $\mathrm{F}^{-}$to the chloride electrolyte. The induction periods which occur for low levels of $\mathrm{F}^{-}$addition indicate that the activation process is dependent on the amount of $\mathrm{F}^{-}$added, attack being almost instantaneous for amounts in excess of $10^{-3} \mathrm{M}$. Indeed for the higher levels of addition the OCP values are close to the theoretical value for bare $\mathrm{Al}$, suggesting perhaps complete removal of the oxide film. It seems rather unusual then that the

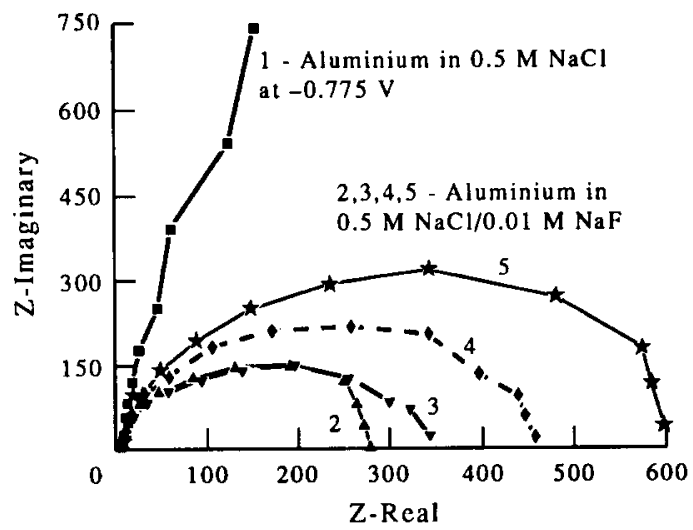

FIG. 8. Nyquist plots for (1) $\mathrm{Al}$ in $0.5 \mathrm{M} \mathrm{NaCl}$ solution at a potential of $-775 \mathrm{mV}$ (SCE); after a 20 -min passivation period $10^{-2} \mathrm{M} \mathrm{NaF}$ was added, and further data was collected after (2) $30 \mathrm{~min}$, (3) $1 \mathrm{~h}$, (4) $3 \mathrm{~h}$ and (5) $24 \mathrm{~h}$ in this solution. 


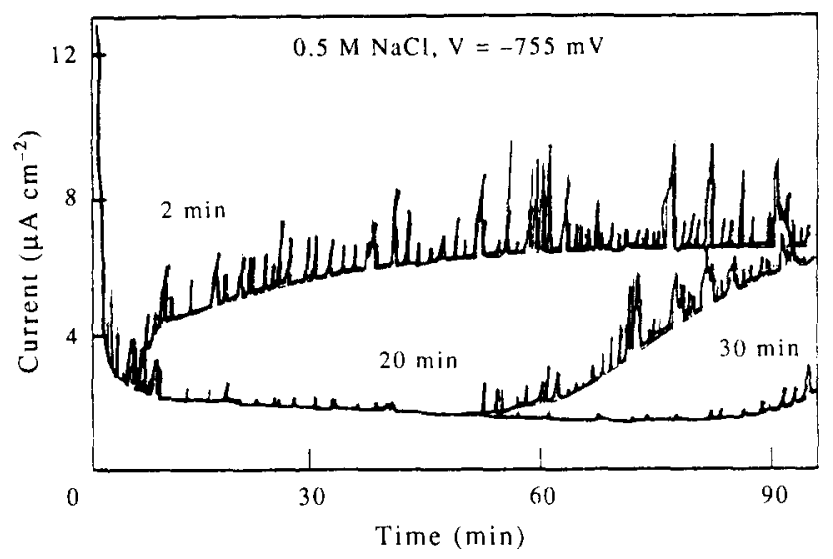

FIG. 9. Current time plots recorded for $\mathrm{Al}$ at a potential of $-755 \mathrm{mV}(\mathrm{SCE})$ in a $0.5 \mathrm{M}$ $\mathrm{NaCl}$ solution to which $10^{-3} \mathrm{M} \mathrm{NaF}$ was added after the time periods indicated.

potentiodynamic data presented in Fig. 4 do not reveal any dependence of the breakdown or pitting potential on the $\mathrm{F}^{-}$concentration. Indeed apart from the anodic maximum observed for the $0.5 \mathrm{M} \mathrm{F}^{-}$addition the passive currents and pitting potentials are almost identical, regardless of the $\mathrm{F}^{-}$concentration or $\mathrm{pH}$ (Table 2).
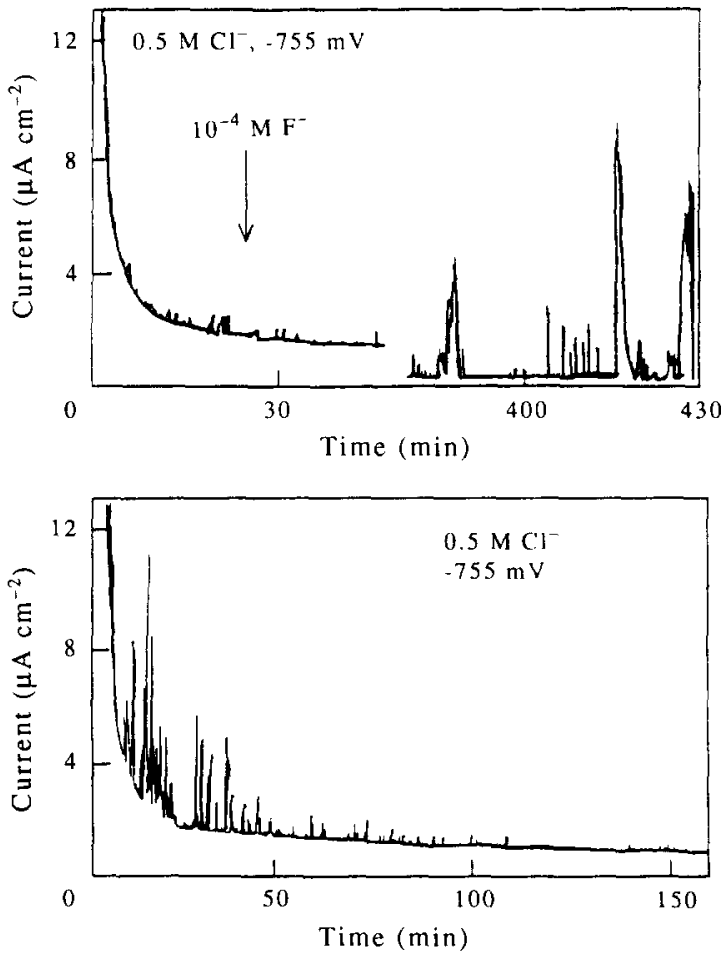

FIG. 10. (a) Current decay profile for $\mathrm{Al}$, recorded in $0.5 \mathrm{M} \mathrm{NaCl}$ at a potential of $-755 \mathrm{mV}(\mathrm{SCE}) ; 10^{-4} \mathrm{M} \mathrm{NaF}$ added after $20 \mathrm{~min}$ of passivation. (b) Current decay profile for $\mathrm{Al}$ at $-755 \mathrm{mV}(\mathrm{SCE})$ in $0.5 \mathrm{M} \mathrm{NaCl}$. 
Table 3. Steady-state potential as a function of $\left[\mathrm{Cl}^{-}\right],\left[\mathrm{F}^{-}\right]=10^{-3} \mathrm{M}$

\begin{tabular}{lc}
\hline$\left[\mathrm{Cl}^{-}\right] / \mathrm{mol} \mathrm{dm}^{-3}$ & Potential $/ \mathrm{mV}$ \\
\hline 3.0 & -1325 \\
2.0 & -1335 \\
1.0 & -1330 \\
0.5 & -1340 \\
0.1 & -1340 \\
0.05 & -1345 \\
\hline
\end{tabular}

Reliance on this potentiodynamic data would certainly lead to the conclusion that fluoride had very little influence on the stability of passive films formed on $\mathrm{Al}$ in chloride solution. Potentiostatic tests in the mixed electrolyte solution give very different and, to a certain degree, somewhat surprising results. Regardless of the method of addition, the presence of $\mathrm{F}^{-}$in the $0.5 \mathrm{M} \mathrm{Cl}^{-}$electrolyte, is seen to result in a very considerable decrease in oxide stability (Figs 5-8). The most unusual aspect of these results, however, is the fact that this instability is only evident in the concentration range $10^{-4} \mathrm{M}-0.25 \mathrm{M} \mathrm{F}^{-}$at room temperature. Outside this concentration range the oxide seems to remain unaltered. The presence of $\mathrm{F}^{-}$results in an increase in the number and particularly the size of current fluctuations superimposed on a gradual current increase. These effects are particularly pronounced for $\mathrm{F}^{-}$ concentrations in the range $10^{-1}-5.0 \times 10^{-3} \mathrm{M}$, while for $>0.25 \mathrm{M} \mathrm{F}^{-}$, the decay profiles are very similar to those observed in $\mathrm{Cl}^{-}$only solutions. This concentration dependence is again evident from the impedance data in Figs 6 and 8 , the $10^{-2} \mathrm{M} \mathrm{F}^{-}$ addition resulting in what are fairly active dissolution rates over the $24 \mathrm{~h}$ test period, in contrast to the more passive behaviour observed for the $0.25 \mathrm{~m}$ addition (Fig. 6). These effects are rather surprising as one would expect that increased levels of $\mathrm{F}^{-}$ would result in increased attack on the oxide.

The extent to which $\mathrm{F}^{-}$additions lead to a decrease in the protective nature of the oxide film on $\mathrm{Al}$ is found to be markedly dependent on the quality of the film formed prior to $\mathrm{F}^{-}$addition, as shown in Fig. 9. It is also important to note that once activation has occurred, the current increases and transients are very similar after the

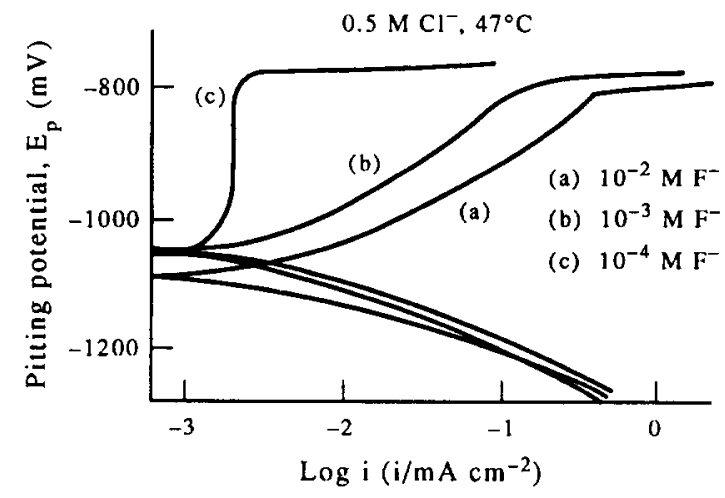

FIG. 11. Potentiodynamic polarization plots recorded for $\mathrm{Al}$ at $47^{\circ} \mathrm{C}$ in the solutions indicated. 


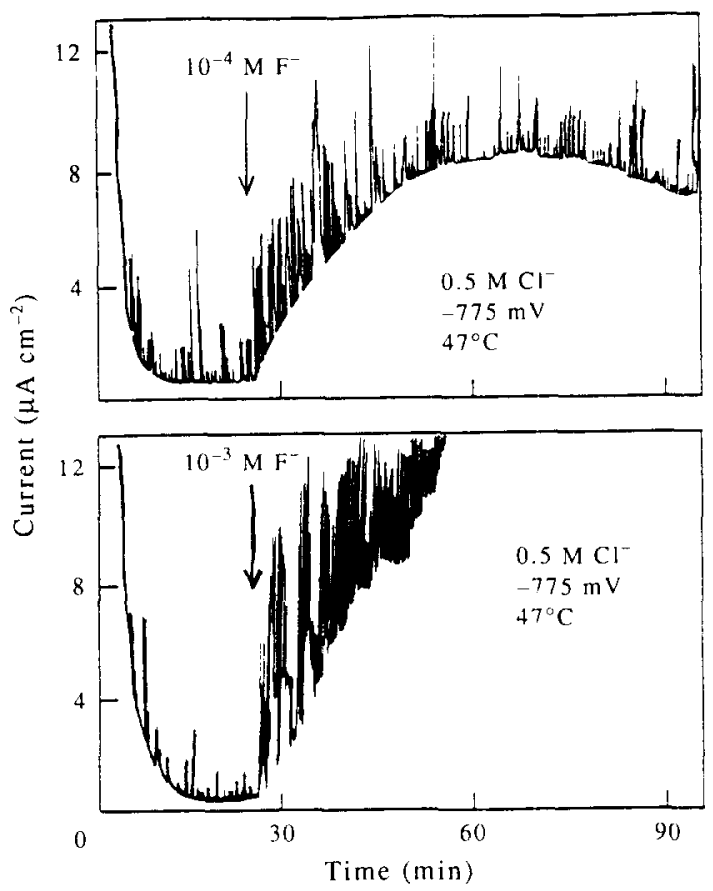

Fig. 12. Current time plots recorded for $\mathrm{Al}$ at a potential of $-775 \mathrm{mV}(\mathrm{SCE})$ and a solution temperature of $47^{\circ} \mathrm{C}$; NaF was added after a 30 -min passivation period to the $0.5 \mathrm{M} \mathrm{NaCl}$ electrolyte, to give the $\mathrm{F}^{-}$ concentrations indicated.

elapse of an appropriate period of time. The improvement in film quality with time of passivation, observed for $\mathrm{Al}$ in chloride solution and manifested by a decrease in the number and size of current fluctuations on current decay profiles ${ }^{2}$ (Fig. 10b) is attributed to a healing of flaws in the developing film. That this does not happen in the presence of fluoride (Fig. 10a), even at a level of $10^{-4} \mathrm{M}$, suggests that $\mathrm{F}^{-}$must play a part in the prevention of these flaw healing processes (film improvement reactions) thus facilitating continued attack by $\mathrm{Cl}^{-}$at the oxide surface.

It is clear from the results so far presented that the amount of $\mathrm{F}^{-}$added to the $0.5 \mathrm{M} \mathrm{Cl}^{-}$electrolyte has a very pronounced influence on events occurring at the oxide-solution interface. The opposite effect, however, is not the case for $\mathrm{Cl}^{-}$as indicated in Table 3. Moreover an induction period was not observed at any concentration and all specimens remained active for periods greater than $12 \mathrm{~h}$. Potentiostatic current-time transients exhibited the same characteristic features: a current increase, and provided that the passivation potential was correspondingly close to the actual pitting potential for that $\mathrm{NaCl}$ concentration, a greater population of activation events. It may be deduced that the composition of the oxyfluoride film remains independent of the bulk chloride concentration.

Unlike the results obtained at $20^{\circ} \mathrm{C}$, an increase in the test solution temperature to $47^{\circ} \mathrm{C}$ results in what appears to be a much more clear influence of $\mathrm{F}^{-}$concentration on the shape of the polarisation plots (Fig. 11). At this temperature the magnitude of the passive current and the pitting potential are now very clearly dependent on the level of fluoride added to the test electrolyte. The higher sensitivity of the potentio- 
dynamic technique at this temperature must be associated with much more rapid reactions occurring at the oxide solution interface. This increased sensitivity to fluoride concentration is again evident from potentiostatic tests (Fig. 12). For a $10^{-3} \mathrm{M} \mathrm{F}^{-}$addition, activation is more rapid than at room temperature and the level of $\mathrm{F}^{-}$required to cause activation is decreased to $10^{-4} \mathrm{M}$. At higher temperatures it may be that this level would be decreased further.

It may be inferred from the results so far presented for $\mathrm{Al}$ in $\mathrm{Cl}^{-}+\mathrm{F}^{-}$solutions that the fluoride ion does not lead to localised attack at the oxide surface, but modifies the oxide in such a way as to facilitate attack by chloride ion. This is supported by the results presented in Fig. 13; here $10^{-2} \mathrm{MF}^{-}$is added after $20 \mathrm{~min}$ to a $0.5 \mathrm{M} \mathrm{SO}_{4}^{2-}$ electrolyte at a potential of $-755 \mathrm{mV}(\mathrm{SCE})$ and to a $0.5 \mathrm{M} \mathrm{Cl}^{-}$ electrolyte at a potential of $-870 \mathrm{mV}(\mathrm{SCE})$. There are no current peaks or fluctuations on the current time profiles as sulphate does not cause pitting attack ${ }^{11}$ and chloride is unable to promote pitting attack at the selected potential. In each case a current increase is observed after addition of the fluoride, indicating a modification or thinning of the surface film. These changes are not instantaneous. A period of time elapses before steady state conditions prevail again. It seems reasonable to assume also that these modifications of the oxide begin at flaws in the developing surface layer, ${ }^{18,19}$ with the number of flaws decreasing with time of passivation thereby leading to longer induction periods (Fig. 9). These modifications may be a result of ion exchange processes, the aggressive $\mathrm{F}^{-}$ion in solution exchanging with $\mathrm{O}^{2-}$ ions in the oxide lattice, ${ }^{20}$ with a consequent lowering of the ionic resistance of the alumina surface film. With the $\mathrm{F}^{-}$ion in the electrolyte preventing further healing of flaws, conditions are now such that attack by $\mathrm{Cl}^{-}$is greatly facilitated, as is seen on the current decay profiles. The fact that these surface modifications of the film are time dependent, may be the reason for the similarity of the potentiodynamic data obtained at $20^{\circ} \mathrm{C}$ (Fig. 4). The time scale of these experiments must be such that sufficient time had not elapsed to allow for reactions leading to alterations in the protective nature of the films. At higher temperatures these reactions are accelerated, thus allowing the $\mathrm{F}^{-}$influence to be recorded (Fig. 11).

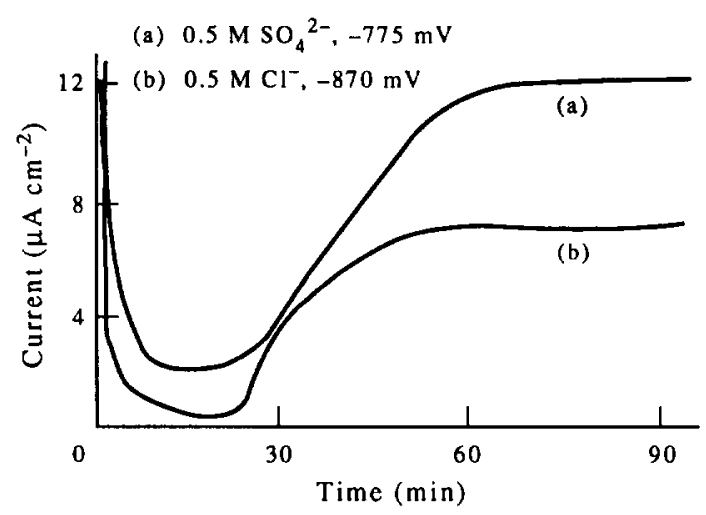

Fig. 13. Current time profiles recorded for (a) $\mathrm{Al}$ at a potential of $-755 \mathrm{mV}(\mathrm{SCE})$ in $0.5 \mathrm{M} \mathrm{Na}_{2} \mathrm{SO}_{4}$ and (b) in $0.5 \mathrm{M} \mathrm{NaCl}$ at a potential of $-870 \mathrm{mV}(\mathrm{SCE}) .10^{-2} \mathrm{M} \mathrm{NaF}$ was added to each solution after a 20-min passivation period. 

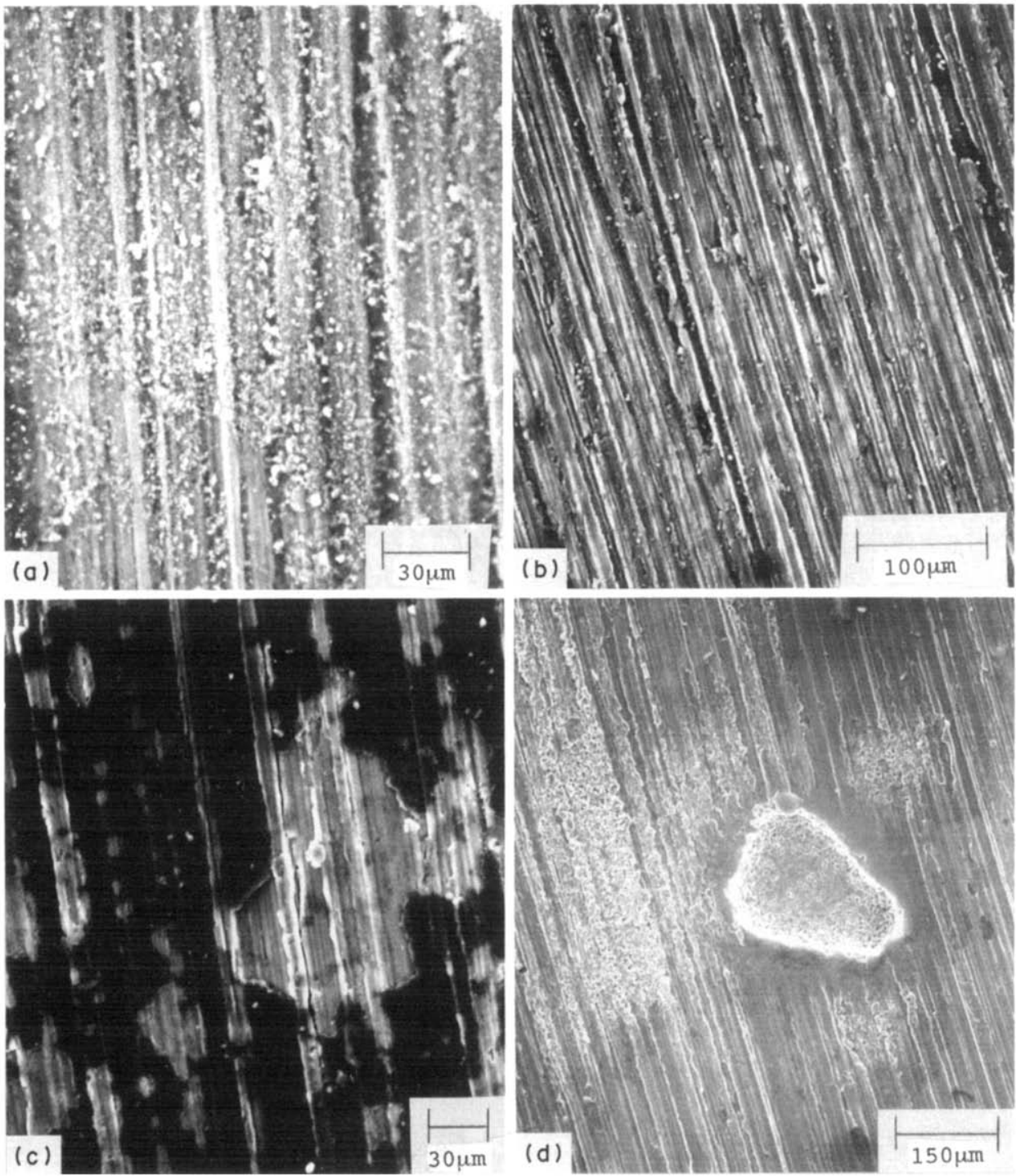

FIG. 14. Electron micrographs of the surface of Al samples held at a potential of $-755 \mathrm{mV}$ (SCE) in $0.5 \mathrm{M} \mathrm{NaCl}$ solution to which (a) $10^{-1} \mathrm{M} \mathrm{NaF}$ and (b) $0.5 \mathrm{M} \mathrm{NaF}$ had been added; (c) surface of sample shown in Fig. 14(a) after ultrasonic cleaning and (d) attacked areas on the surface of this sample. 